\title{
Research on Elements of Independent English Study of College Students in Network Era
}

\author{
Haifen Liu \\ School of Foreign Languages, Yan'an University, Yanan Shaanxi, 716000, China
}

Keywords: Network era, College students, Elements of independent English study, Research

\begin{abstract}
With the constant deepening and reform of Chinese education and the constant development of network technology, traditional educational and teaching mode has been gradually eliminated and new teaching mode has emerged. English teaching plays a decisive role in college teaching, which has great influence on future employment development of students. In view of this, new curriculum standard has raised higher requirements for college English teaching. Teachers should not only impart English knowledge to students, but also train their ability of independent study. However, as teachers are seriously influenced by traditional teaching concept, there are some problems in the training of students' ability of independent study. Therefore, colleges and universities decide to start with the study on elements of independent study and implement teaching after thorough research on learning elements, which can yield twice the result with half the effort. Therefore, this paper conducts in-depth study on elements of independent English study of college students in network era, describes its own opinions and expects to provide help for college teachers to implement English teaching well and train students' ability of independent English study better.
\end{abstract}

\section{Introduction}

Colleges and universities are major sites for the cultivation of talents required by the society, which have important influence on long-term development of the country. As a language most widely applied in the world, English has raised great attention of the country in the gradual development process of global economic integration. Therefore, the status of English teaching has increased and teachers attach more and more importance to the cultivation of students' ability of independent study in teaching in the current network era. However, the implementation of such teaching work is somewhat difficult for students and teachers adapting to traditional teaching methods. In view of this, colleges and universities organize elements of independent study, analyze the information of English study fed back by students under the background of network era based on their actual teaching resources and teaching theories and then put forward more effective English teaching strategies so as to improve the level of college English teaching and train more English talents.

\section{Relevant elements of independent study}

There are different definitions of independent study in foreign countries. Different researchers have different opinions. For example, Holec thought, "independence is an ability of effective self-control mainly involving the selection of learning method and the establishment of learning objectives etc." This school of thought pays more attention to students' self-management ability ${ }^{[1]}$.Little corrected such opinions and thought that the way how to organize learning should be included. Therefore, it can be found through the integration of independent study definitions of multiple schools that elements of independent study mainly include learning methods, plan and contents etc.

\section{Practical research on elements of independent English study of college students in network era}

Elements of independent study of college students mainly include learning contents, plan, time and introspection. To conduct in-depth study on elements of independent study, it is required to discover its advantages through practical comparison. Therefore, this paper analyzes the application 
of elements of independent English study of college students in practical teaching and shows functions of English study elements more clearly through the comparison of control group and experimental group.

\section{Initial preparation of experiment}

First, the status of experimental group and control group in the initial stage of experiment is analyzed. It is required to understand and record English study motivation, method and plan etc. of students in control group and experimental group during the experiment as control data in the later period of the experiment. In this experiment, freshmen in the Department of Chinese Language and Literature of a university are selected. There are 124 students in experimental group, 64 of whom are in the class of English improvement and 60 of whom are in the follow-up class. There are 110 students in control group, all of whom are in the class of English improvement. According to the survey on learning methods of students in both groups, 68.3\% students in experimental group use the method of passive acceptance and only 31.7\% students use independent study method.69.1\% students in control group use the method of passive acceptance and 31.9\% students use independent study method.

Second, the academic performance of students in experimental group and control group in the initial stage of experiment is analyzed. According to the survey and comparison of English results in college entrance examination of students in both groups, their English performance does not differ a lot. According to the analysis with EXCEL software, the average English score of students in experimental group is only slightly higher than that of students in control group [2].Meanwhile, the performance of students in both groups in entrance examination is also analyzed. It is found that their performance difference is not significant. According to the analysis on their learning plan and method etc., they are basically the same.

\section{Experimental process}

The main purpose for carrying out the experiment is to compare independent English study of college students under the background of network era and traditional teaching methods, find out relevant laws and existing problems and then put forward effective countermeasures. The main difference between independent study and traditional teaching mode is teaching mode, i.e. different external elements. Therefore, it is necessary to analyze elements of independent study in the experimental process. The experiment should follow the process below:

First, illustrate network environment. In recent years, the scope of application of network technologies has been expanded obviously in its constant development process and it has been gradually applied in education and teaching. For English teaching in network environment, teachers should arrange network courseware study for students. That is, teachers should use network courseware for teaching and meanwhile allow students to study English independently and learn some knowledge outside the textbook with network course.

Second, analyze traditional classroom teaching mode. In traditional classroom teaching, teachers impart knowledge with spoon-feeding teaching method and students can only accept the knowledge passively. They have few opportunities for independent study of English knowledge.

Finally, contrast and make a conclusion. According to comparison, English teaching in network era mainly uses network technologies and students have sufficient time for independent study. Traditional classroom learning mainly depends on teachers. There is little application of network technology and students have few opportunities and little time for independent study. According to the comparison of both learning methods, they have similarities in content. However, network teaching is more abundant than traditional teaching and independent study has differences.

\section{Analysis on elements of independent study in final stage of experiment}

Elements of independent study can be analyzed in the following aspects:

First, analysis on learning motivation. Among students in experimental group, $48.7 \%$ have instrumental learning motivation and $51.3 \%$ have comprehensive learning motivation. Among students in control group, $60.3 \%$ have instrumental learning motivation and $39.7 \%$ have comprehensive learning motivation. They have significant differences. Instrumental motivation mainly refers to the obtainment of certificates for passing CET4 and CET6 and entry into a higher 
school etc. Comprehensive motivation mainly refers to going abroad etc. Both motivations can promote students in learning English knowledge. However, comprehensive motivation has more significant functions ${ }^{[3]}$.It is clear that students in experimental group are better than those in control group in terms of learning motivation. Meanwhile, the rate of students in control group having comprehensive learning motivation is increasing.

Second, analysis on learning method. Among students in experimental group, 3.6\% study with spoon-feeding method and $96.4 \%$ use independent study method, which increase greatly compared to the data in the initial stage. Among student in control group, $54.7 \%$ use spoon-feeding study method and $45.3 \%$ use independent study method. According to the comparison, the number of students in experimental group using independent study method is greater than that in control group, who have significant advantages. Moreover, the number of students in control group using independent study method has increased.

Third, analysis on learning plan. Both groups have great progress in terms of learning plan. There are more students making weekly plan in the experimental group than control group, indicating that students attach more and more importance to the tightness of plan. The learning mode in network era impels students to attach more importance to the control of learning process.

Forth, analysis on learning time. According to the analysis on learning time, the learning time of students in both groups increases. However, viewed as a whole, students in experimental group have more learning time than those in control group and they have strong ability of retrospection. The main reason is the establishment of independent study environment. Students think more while being responsible for themselves.

Fifth, analysis on learning retrospection. More students in experimental group conduct retrospection than control group and the number of students conducting retrospection increases obviously compared to the initial stage. This indicates that independent study of students in network environment can impel them to retrospect more and then improve their learning abilities.

Analysis on academic performance in final stage of experiment. According to the analysis on academic performance in the final stage of experiment, students in both groups have significant differences in academic performance. According to the calculation with EXCEL software, the average English score of students in experimental group is 69.13 and that of students in control group is 72.67. It is clear that students in experimental group have a higher average score than those in control group. That is to say, students in experimental group have strong independent study ability and therefore have a higher score .

Conclusion. According to the analysis on experimental contents, it can be concluded that internal elements of independent study change in the process of change of its external environmental elements. Therefore, internal learning elements in independent study mode in network era and traditional learning mode change towards a positive direction. However, according to the analysis on the overall situation, independent study in network environment changes more significantly and students have more obvious learning effect. There are some main reasons for this as below:

First, independent study of students in both network environment and traditional environment has certain progress mainly because that the importance of independent study is realized in teaching and meanwhile teachers give full play to their guiding ability; students move forward constantly under the correct guidance of teachers and apply the English knowledge learnt flexibly. In such case, their interest in learning English is aroused and their enthusiasm about learning is motivated. Therefore, their internal elements in independent study process gradually progress and gradually impel the improvement of students' academic performance.

Second, the main reason for better effect of independent study of students in network environment is that teachers can teach with network technologies in network environment, thus enriching teaching methods and resources. Meanwhile, the application of such teaching method also makes up for deficiencies in traditional teaching and increases independent study time of students. Therefore, students have more time to establish learning objectives and plan and internal elements of their independent study change positively. Hence, independent study of college English in network 
environment can achieve better effect. In addition, independent study in network environment can manifest students' personality, stimulate their desire for learning and improve their learning effect.

\section{Inspiration}

According to the analysis on contents above, the following inspirations can be obtained: first, teachers and students should deeply realize that language study requires practice and students should study independently in the practical process. Only in this way can students use the language flexibly. Therefore, it is necessary to enhance the support for the second classroom in the teaching process. Teachers should transform their own teaching concepts. Instead of considering English teaching as simple knowledge, they should provide students with more opportunities for practice in teaching and allow them to memorize the knowledge more deeply in practice.

Second, while encouraging students to study independently, teachers can not neglect their own guiding role. Independent study of students does not mean that teachers should let students run their own course. Instead, teachers should return the initiative to students. When students make mistakes in the process of independent study, teachers should give correct guidance. That is to say, though teachers should not intervene in students' study, they should indicate the direction for them and impel them to study independently in a correct way. Meanwhile, teachers should attach importance to their supervising role and provide timely guidance if finding any problem in the process of supervising the learning process of students strictly. They should guarantee the correctness of students' learning path ${ }^{[5]}$.

Third, when using network technologies in teaching, teachers should first make network courseware and guarantee close relation between courseware and teaching contents so as to give full play to network teaching materials in the process of teaching with courseware, improve students' independent ability and help them master more English knowledge.

\section{Conclusion}

In conclusion, the coming of network era has changed the life and work pattern of people and meanwhile impacted English teaching in colleges and universities. The application of network technologies in teaching by teachers has achieved significant effect, improved the efficiency of classroom teaching effectively and motivated students' initiative in English learning. Meanwhile, students' ability of independent study has been cultivated in network environment. Independent study of students will promote the development of internal elements of independent study. The development of elements will promote students' learning. Therefore, they supplement each other. In such case, it is very necessary for colleges and universities to train students' ability of independent study.

\section{References}

[1] Zhou Li. Formation of Independent English Study Platform of Students in Network Environment . Overseas English (I), 2013(7):72-73.

[2] Lv Chenjie. Discussion on Independent College English Study Based on Network Multimedia Environment . Journal of Harbin Vocational College, 2013(5):82-83.

[3] Wang Shan. Experimental Study on How to Improve Independent English Study Ability of Students in Higher Vocational Colleges in Multimedia Aided Teaching Environment. Hebei Normal University, 2013.

[4] Cao Yanchun. Investigation on Status of Independent English Study Ability of Students on Network Independent Study Platform and Countermeasures - Take Xinjiang Agricultural University for Example . China Extension Education (Last Third of the Month), 2013(9):126-127.

[5] Hai Xia. Endeavor to Train and Improve Independent English Study Ability of College Students - Problems in Construction and Use of Network College English Teaching Resource Library in 
Xinjiang University and Countermeasures . Journal of Xinjiang Radio and Television University, 2010(3):40-43. 